\title{
The long-term metabolic function of intraportal and renal subcapsular islet isografts and the effect on glomerular basement membrane thickness in rats
}

\author{
C.K.Leow, D. W. R. Gray, P.J. Morris \\ Nuffield Department of Surgery, University of Oxford, The John Radcliffe, Headington, Oxford OX3 9DU, UK
}

\begin{abstract}
Summary Previous studies of intraportal islet autotransplantation in large animals have reported graft failure after months or years. In the rat it has been reported that intraportal islet isografts eventually failed whilst islets transplanted to the renal subcapsule functioned up to a year. We made Dark Agouti (DA) rats severely diabetic with streptozotocin, then 1000 or $3000 \mathrm{DA}$ islets were transplanted beneath the renal capsule or into the liver. One set of transplanted rats and untreated diabetic and normal non-diabetic littermates were monitored lifelong by measurement of plasma glucose, others were killed at 6,12 and 18 months for measurement of haemoglobin $\mathrm{A}_{1 \mathrm{c}}$, intravenous glucose tolerance test, pancreas insulin content and histology of the kidney. Renal glomerular basement membrane thickness was measured by the orthogonal intercept method. The results showed that intraportal isografts reversed hyperglycaemia significantly faster than renal subcapsular isografts. In the renal subcapsular site, consistent reversal of diabetes was achieved with 3000 islets but
\end{abstract}

not with 1000 islets. Furthermore, intraportal islet grafts with 3000 islets led to lower, normal random glucose level than renal subcapsular grafts for the first 13 months. Normoglycaemia was maintained lifelong in all rats that achieved early normoglycaemia after transplantation of 3000 islets, irrespective of the site of islet transplantation. The fasting glucose, haemoglobin $A_{1 c}$ levels, $K$ value and glomerular basement membrane thickness of the recipients of 3000 islets to either the intraportal and subcapsular site were not significantly different from each other and the normal controls up to 18 months. We conclude that, in streptozotocin diabetic DA rats, normoglycaemia following transplantation of an adequate mass of pancreatic islet tissue (3000 islets) to the liver or beneath the renal capsule is lifelong and the development of glomerular basement membrane thickening is prevented. [Diabetologia (1995) 38: 1014-1024]

Key words Rat, pancreatic islet, transplantation, diabetes mellitus, nephropathy.
The late complications of insulin-dependent diabetes mellitus are a consequence of the hyperglycaemic state, as shown by the effect of maintaining tight glycaemic control using exogenous insulin, which influences the clinical course of diabetic complications [1-

Corresponding author: Mr. D.W.R. Gray, Clinical Reader in Transplantation, Nuffield Department of Surgery, John Radcliffe Hospital, Headington, Oxford OX3 9DU, UK Abbreviations: HBSS, Hanks' balanced salt solution with $\mathrm{HE}-$ PES buffer; IP, intraportal; SC, renal subcapsular; IVGTT, intravenous glucose tolerance test; GBMT, glomerular basement membrane thickness; ANOVA, analysis of variance; $\mathrm{HbA}_{1 \mathrm{c}}$, haemoglobin $\mathrm{A}_{1 \mathrm{c}}$; DA rats, Dark Agouti rats.
4]. One approach to achieving tight glycaemic control is by transplantation of insulin secreting tissue, either as a vascularized pancreatic graft or free grafts of islets. Vascularized pancreas transplantation is now a routinely successful procedure in diabetic patients, usually performed in combination with a kidney transplant in patients with diabetic renal failure, and good glycaemic control is usually achieved. Although there is some evidence to suggest that a successful vascularized whole organ pancreatic graft can halt the progression of diabetic complications in a newly transplanted kidney [5], pancreas transplantation has little effect on established retinopathy [6, 7] or nephropathy [8], but possibly some beneficial effect on neurop- 
athy $[9,10]$. These findings suggest that earlier transplantation, soon after the development of diabetes, may be required to prevent complications, and experimental studies of vascularized pancreas transplantation in rodents have shown that lifelong cure of experimental diabetes by early transplantation with prevention of the development of complications is possible $[11,12]$. However, vascularized pancreas transplantation is a major procedure that is unlikely to be justifiable in the young diabetic patient. The alternative of separating the pancreatic islets, allowing transplantation of the islets alone to achieve physiological normoglycaemia, is a logical approach especially if the transplant procedure were both safe and simple, making it applicable to young diabetic patients.

Recent reports of successful clinical islet transplantation have been encouraging [13-15], although the duration of function of these grafts has generally been short. The reason for the eventual failure of most of the grafts has not been clear, but must be viewed against the similar failure of long-term islet grafts in dog [16] and monkey [17] models. Clearly, there is little point in pursuing islet transplantation for clinical use if the grafts will inevitably fail within a few months. The identification of the cause and the eventual prevention of graft failure in the above experiments is of crucial importance for the future clinical application of islet transplantation.

In the inbred rodent it is possible to transplant islets without restrictions on the mass of islets used for the transplant, and to examine the effect of transplanting islets to different sites. Interestingly, despite the fact that numerous experiments in diabetic rodents (both rats and mice) have documented the metabolic efficiency of islet transplantation and its effect on diabetic complications, most of these favourable reports have only examined short-term function. A longer-term study of islet transplantation in comparison to vascularized pancreas transplantation in the rat suggested that the islet grafts eventually failed and did not prevent long-term development of complications [18], and a further report suggested that long-term failure of islets might be related to the use of the intraportal transplantation site [19].

We have undertaken a study of long-term (lifelong) islet isograft function in Dark Agouti (DA) rats, transplanting an increasing mass of islets into both the intraportal and renal subcapsular sites. In addition we have examined the influence of these grafts on the development of long-term diabetic complications in the form of diabetic glomerulopathy.

\section{Materials and methods}

Experimental animals. Female DA (RT1 ${ }^{\mathrm{a}}$ ) rats obtained from Olac Ltd., Bicester, Oxon, UK. were used throughout the experiment. The principles of laboratory animal care were fol- lowed under United Kingdom Home Office licence. Eightweek-old littermates weighing $140-170 \mathrm{~g}$ were used in the study. Normal and islet grafted animals were housed in standard rat cages layered with fresh dust-free wood shavings, diabetic animals were housed in wire bottomed cages, four to a cage. All animals were supplied with Beekay laboratory rat chow (Bantin and Kingman Ltd., Hull, North Humberside, UK) and water ad libitum.

Induction of diabetes. Diabetes was induced under ether inhalation anaesthesia by injection of streptozotocin (Sigma, Poole, Dorset, UK) in citrated buffer via an inferior tongue vein using a 26 gauge needle. The dose of streptozotocin was $65 \mathrm{mg} / \mathrm{kg}$ for those animals studied for 6 and 12 months and $55 \mathrm{mg} / \mathrm{kg}$ for animals studied for over 12 months. Plasma glucose was measured using a tail vein blood sample 10 and 14 days after injection and only animals with a random glucose of $25 \mathrm{mmol} / \mathrm{l}$ were entered into the study as recipients or diabetic controls. Islet transplantation was performed within 2 weeks of confirming diabetes.

Islet isolation and purification. Islets were isolated by an intraductal collagenase technique as previously described [20]. In brief, under phenobarbitone anaesthesia the pancreatic duct was cannulated, the animal exsanguinated and the pancreas distended with cold Hanks' balanced salt solution with HEPES $10 \mathrm{mmol} / 1$ (HBSS) containing $3 \mathrm{mg} / \mathrm{ml}$ collagenase (Sigma type V; Sigma). The pancreas was excised and incubated at $37^{\circ} \mathrm{C}$ for $20 \mathrm{~min}$ before cooling and dispersed by gentle shaking. The tissue was passed through a mesh, pore size $500 \mu \mathrm{m}$, and then islets were purified using either a Ficoll (Pharmacia, Milton Keynes, Herts., UK) [21] (groups 1-8) or bovine serum albumin (Advanced Protein Products, West Midlands, UK) [22] (groups 9-13) density gradient.

The islets were suspended in $3 \mathrm{ml}$ of HBSS and $6 \times 25-\mu \mathrm{l}$ samples placed on glass slides; these were examined through a stereomicroscope and the total number of islets having a pearly white appearance was counted. The number of islets in $3 \mathrm{ml}$ was estimated by multiplying the total number of islets in $150 \mu \mathrm{l}$ by a factor of 20 . The correct volume of suspended islets was then aliquoted into two 15 -ml Falcon tubes to give either 1000 or 3000 islets.

Intraportal (IP) islet transplantation. Anaesthesia was induced by ether and maintained with intraperitoneal ketamine hydrochloride $10 \mathrm{mg}$. Through a midline incision the portal vein was identified and exposed. The islets, suspended in $0.4 \mathrm{ml}$ HBSS, were slowly injected into the portal system via a 25 gauge needle placed in the portal vein and the syringe flushed twice by gently aspirating and reinjecting the portal blood.

Renal subcapsular (SC) islet transplantation. The recipient was anaesthetised as above. Transplantation of islets was performed using the blood-clot technique as previously described [23]. Briefly, the islets were accumulated in a conical shaped receiver and gently mixed with approximately $20 \mu \mathrm{l}$ of tail vein blood from the recipient. A small capsulotomy was performed on the left kidney and the blood clot, containing islets, transferred to a pocket beneath the capsule using microforceps. The islets were gently massaged and spread so that they lay in a thin even layer beneath the capsule.

Experimental groups. The dose of streptozotocin for inducing diabetes and the number of islets within the grafts were not uniform (Table 1). All animals were assigned to each treatment group by using a random table. 
Table 1. Experimental groups

A. Islet-transplanted rats

\begin{tabular}{lllll}
\hline $\begin{array}{l}\text { Experi- } \\
\text { mental } \\
\text { group }\end{array}$ & $\begin{array}{l}\text { STZ } \\
(\mathrm{mg} / \mathrm{kg})\end{array}$ & $\begin{array}{l}\text { Islets } \\
\text { trans- } \\
\text { planted }\end{array}$ & Site & $\begin{array}{l}\text { Time followed } \\
\text { after trans- } \\
\text { plant (months) }\end{array}$ \\
\hline
\end{tabular}

Islet-transplanted rats

$\begin{array}{rrrrll}1 & 65 & 7 & 1000 & \text { IP } & 6 \\ 2 & 65 & 7 & 1000 & \text { SC } & 6 \\ 3 & 65 & 7 & 3000 & \text { IP } & 6 \\ 4 & 65 & 7 & 3000 & \text { SC } & 6 \\ 5 & 65 & 3 & 1000 & \text { IP } & 12 \\ 6 & 65 & 3 & 1000 & \text { SC } & 12 \\ 7 & 65 & 7 & 3000 & \text { IP } & 12 \\ 8 & 65 & 4 & 3000 & \text { SC } & 12 \\ 9 & 55 & 6 & 3000 & \text { IP } & 18 \\ 10 & 55 & 5 & 3000 & \text { SC } & 18 \\ 11 & 55 & 25 & 3000 & \text { IP } & \text { Life } \\ 12 & 55 & 23 & 3000 & \text { SC } & \text { Life }\end{array}$

B. Controls

In addition to the above islet transplanted groups, for each group a number of normal rats and diabetic untransplanted rats from the same batch was followed for 6 months, 12 months, 18 months and lifelong, as appropriate. (The number of controls followed to completion of the respective study periods were: normals $n=7,7,5,48$ diabetics $n=3,3,0,65$, respectively). STZ, Streptozotocin

6- and 12-month study groups (Table 1, transplanted groups $1-$ 8 plus normal and diabetic control groups): Diabetes was induced with intravenous streptozotocin at a dose of $65 \mathrm{mg} / \mathrm{kg}$. Each study period (either 6 or 12 months) consisted of six groups of animals: four groups of diabetic rats given islet grafts: 1000 islets intraportally (1000 IP), 1000 islets under the renal capsule (1000 SC), 3000 islets intraportally (3000 IP), 3000 islets under the renal capsule ( $3000 \mathrm{SC}$ ), one group each of untreated diabetic and normal controls.

18-month study group (Table 1, transplanted groups 9-10 plus diabetic and normal control groups): Diabetes was induced with intravenous streptozotocin at a dose of $55 \mathrm{mg} / \mathrm{kg}$. Four groups of animals were studied: two groups of diabetic animals given islet grafts ( $3000 \mathrm{IP}$ or $3000 \mathrm{SC}$ ), one group each of untreated diabetic and normal controls.

At the end of the 6-, 12- and 18-month study periods, all surviving animals underwent intravenous glucose tolerance test (IVGTT), removal of blood sample for glycated haemoglobin measurements, removal of native pancreas for estimation of total insulin content and six pieces of renal cortical tissue for glomerular membrane thickness measurement.

Lifelong study group (Table 1, groups 11 and 12, plus diabetic and normal controls): Diabetes was induced with intravenous streptozotocin at a dose of $55 \mathrm{mg} / \mathrm{kg}$. Four groups of animals were studied: two groups of diabetic animals given islet grafts ( $3000 \mathrm{IP}$ or $3000 \mathrm{SC}$ ), one group each of untreated diabetic and normal controls. These animals were monitored with random plasma glucose measurement until death from natural causes.

Random plasma glucose measurement. All samples were collected in the afternoon between 16.00 and 19.00 hours. All islet graft recipients underwent plasma glucose measurement just before islet transplantation and then on days $1,3,5,7,10$, 14,21 and 28 post-transplantation and then monthly to the end of the study period. The control animals, both diabetic and normal, underwent monthly plasma glucose measurements to the end of the study period.

Intravenous glucose tolerance test (IVGTT). Owing to United Kingdom Home Office restrictions, all IVGTT tolerance tests in groups 1-8 were performed under light anaesthesia (ketamine $100 \mathrm{mg} / \mathrm{kg}$ ). Because anaesthesia was found to produce an abnormal IVGTT in normal rats (see below) special permission was granted for glucose tolerance tests in restrained rats (after recovery from anaesthesia required for placement of cannulae) in groups 9 and 10. In all animals, following an overnight fast, IVGTT was performed via femoral vein and artery cannulae. Access to water was maintained throughout the fast and the IVGTT. After withdrawing a blood sample for plasma glucose and insulin measurements via the femoral vein cannula, D-glucose, $500 \mathrm{mg} / \mathrm{kg}$ body weight, was injected rapidly into the circulation via the femoral artery cannula. Blood samples were drawn through the femoral vein cannula at $1,3,5,10,20$, 40 and $60 \mathrm{~min}$ following glucose infusion for plasma glucose and insulin measurements. All blood samples were kept on ice and separated as soon as possible. Plasma was separated and frozen immediately. Samples for plasma glucose estimation were processed using a Beckman II glucose analyser (Beckman Ltd., High Wycombe, Bucks., UK). Insulin assay was measured by a single antibody technique [24]. The $\mathbf{K}$ value was calculated according to the method of Moorhouse et al. [25].

Glycated haemoglobin $\left(H b A_{1 c}\right)$ measurement. A quantity $(0.1 \mathrm{ml})$ of fresh blood was mixed with $0.3 \mathrm{ml}$ of haemolysing reagent and the sample thoroughly mixed and allowed to stand at room temperature for $60 \mathrm{~min}$ before storage at $-30^{\circ} \mathrm{C} . \mathrm{HbA}_{1 \mathrm{c}}$ measurement was performed using the Corning electrophoretic procedure on an agar gel medium (Corning Medical, Palo Alto, Calif., USA).

Glomerular basement membrane thickness (GBMT) measurements. The renal specimens were placed in a universal container with $10 \mathrm{ml}$ of $4 \%$ glutaraldehyde and fixed overnight. After washing the specimens were post-fixed in $1 \%$ osmium tetroxide, dehydrated through alcohol baths and finally embedded in Spurr resin.

The true GBMT was measured according to the orthogonal intercept method as described by Hirose et al. [26]. In brief, semithin sections, stained with toluidine blue, were examined under light microscopy to determine the presence of suitable glomeruli for electron microscope study. Once confirmed, ultrathin sections were produced and inspected at low magnification $(\times 550)$ with a Philips EM301 electron microscope. Glomeruli were chosen for study provided the centre of the glomerulus was more than one maximal glomerular radius from the edge of the section. Each glomerular cross-section was then systematically photographed (at a magnification of $\times 2000$ ), advancing to the next field until the whole glomerulus was photographed. At least two glomeruli were photographed from each section. Thirty photographs per experimental animal at a final magnification of $\times 12000$ were studied.

Each of the photographs was superimposed on a specially constructed transparent grid and placed on a light box for illumination. At each point where a grid line intersected the endothelial aspect of the glomerular basement membrane, the GBMT at this point was then measured at a right angle to the surface of the basement membrane using a specially constructed ruler. A minimum of 150 measurements per animal were recorded. The true GBMT, termed "harmonic mean basement membrane thickness" by Hirose et al. [26], was then calculated from the formula provided by Hirose et al. 

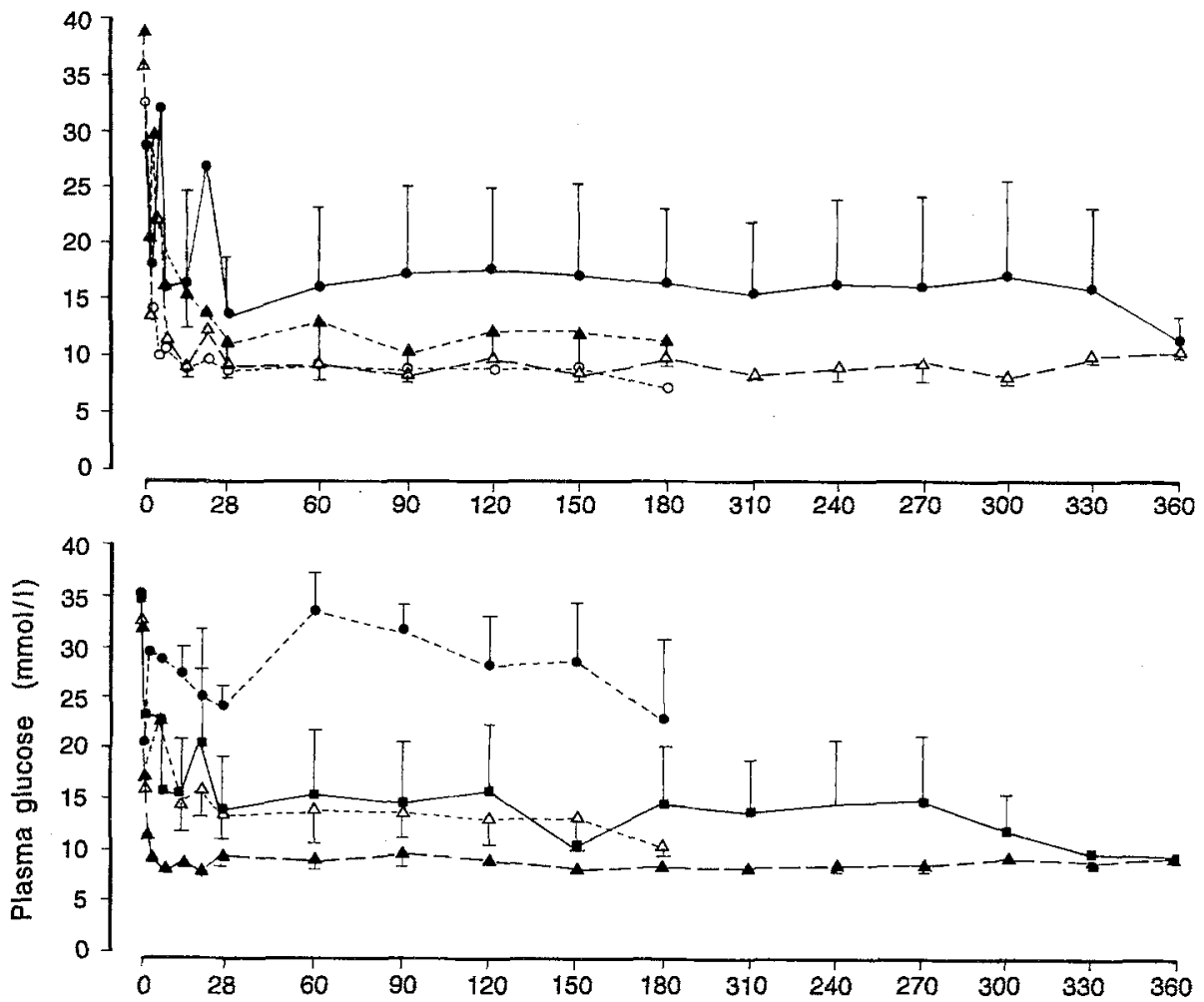

Fig. 1. Non-fasting plasma glucose of rats given 1000 or 3000 islets IP or SC and followed for either 6 months or 12 months, compared to normal and diabetic controls.

$(\triangle--\Delta) 1000$ islets IP followed

6 months, $(\bullet-\cdots) 1000$ islets SC followed 6 months, (O---o) 3000 islets IP followed 6 months, (n) 3000 islets $\mathrm{SC}$ followed 6 months, $(\mathbf{\Delta}-\mathbf{A})$

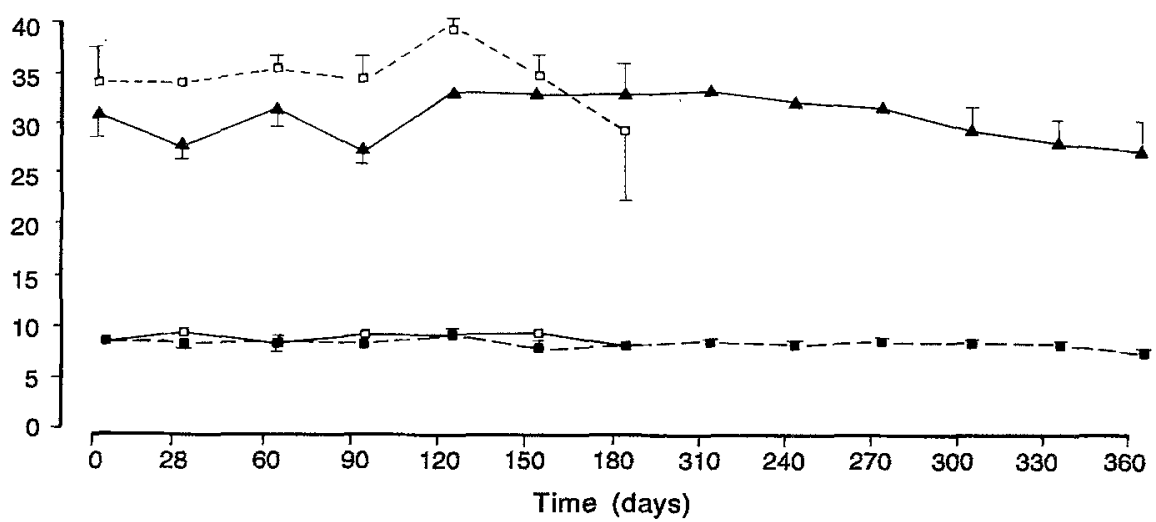
1000 islets IP followed 12 months, $(\bullet) 1000$ islets SC followed 12 months, (A-A) 3000 islets IP followed 12 months, $(\Delta---\Delta) 3000$ islets SC followed 12 months, (ㅁ- $\square$ ) normal controls from 6-month follow up groups, (--) normal controls from 12-months study groups, ( $\square---\square)$ diabetic controls from 6-month study groups, $(\mathbf{A}-\mathbf{A})$ diabetic controls from 12-month study groups. Error bars indicate SEM

\section{Statistical analysis}

All results are expressed as means \pm SEM unless otherwise stated. Statistical analyses were performed with the SAS Release 6.03 Edition statistical package (SAS Institute Inc.). The data were analysed within the framework of the General Linear Models for the analysis of variance (ANOVA), especially for unbalanced data. One-way ANOVA with Bonferroni T-test was performed on the random glucose, $\mathrm{HbA}_{1 \mathrm{c}}$ and insulin content results. Where appropriate, two-way ANOVA, a factorial model with interaction, was performed on the effects of dose of islets grafted and the site of implantation. Significance of differences was evaluated at the $5 \%$ level.

\section{Results}

6- and 12-month study groups (Fig. 1). The starting level of hyperglycaemia in the diabetic controls and diabetic animals treated with islet grafts was not signifi- cantly different. Animals grafted with 1000 islets IP and monitored over 6 months had a lower plasma glucose level than the $1000 \mathrm{SC}$ animals $(14.67 \pm 2.5$ vs $27.57 \pm 2.7 \mathrm{mmol} / 1$, day $14, p=0.0037$ ). The $1000 \mathrm{SC}$ animals which survived the whole 6 months in fact remained diabetic while the $1000 \mathrm{IP}$ animals had glycaemic levels similar to normal controls. The 1000 IP animals in the 12-months study also maintained a lower glycaemic level than the $1000 \mathrm{SC}$ animals $(9.07 \pm 1.2$ vs $13.27 \pm 5.5 \mathrm{mmol} / 1,1$ months) but this did not reach statistical significance. This lower glycaemic level shown by animals with intraportal grafts was also apparent in animals grafted with 3000 islets. The glycaemic level of the animals with $3000 \mathrm{IP}$ against those with $3000 \mathrm{SC}$ was $8.71 \pm 0.5 \mathrm{vs} 15.256 \pm 3.1 \mathrm{mmol} / \mathrm{l}$ (6month study) and $9.57 \pm 1.0$ vs $13.93 \pm 5.4 \mathrm{mmol} / 1$ (12-month study). This difference again did not reach statistical significance. The glycaemic level of those successfully grafted animals in the 6- and 12-month 


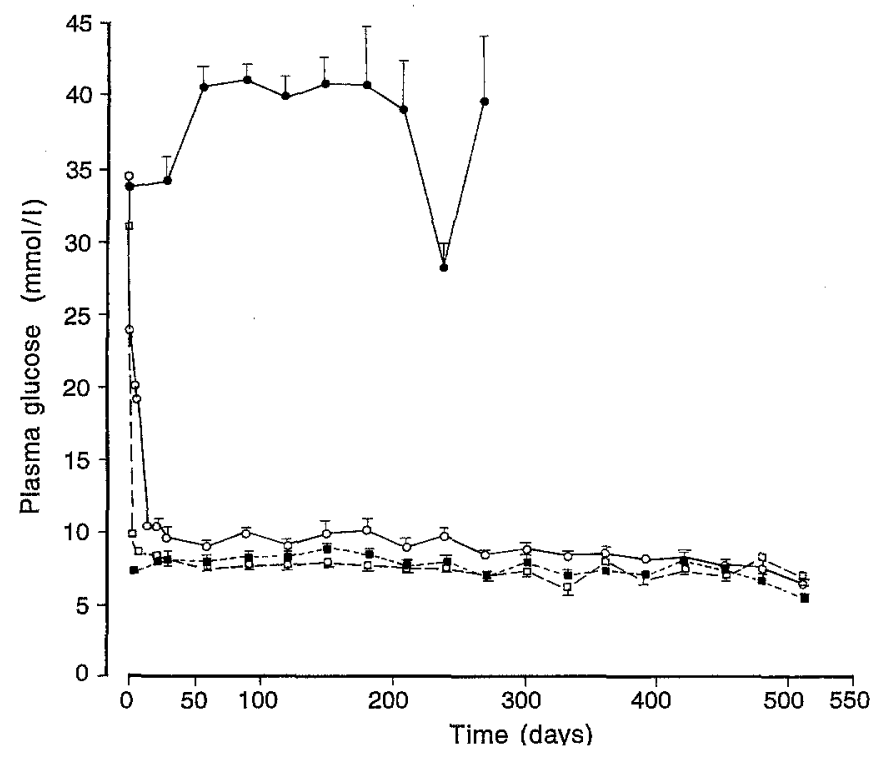

Fig. 2. Non-fasting plasma glucose of rats made diabetic with streptozotocin $55 \mathrm{mg} / \mathrm{kg}$ then transplanted with 3000 islets either IP or SC and followed for 18 months, compared to normal and diabetic controls. ( $(-\cdots)$ ) Normal controls, $(\bullet)$ diabetic controls, (ㅁ---[) 3000 islets IP, (०—) 3000 islets SC. Error bars indicate SEM. Note that the untransplanted diabetic rats did not survive beyond 270 days

study periods was not significantly different from that in normal controls $(9.20 \pm 0.4$ and $8.56 \pm 0.4 \mathrm{mmol} / \mathrm{l}$, respectively). Once the hyperglycaemia was successfully reversed by islet transplantation, the animals remained normogycaemic throughout the whole 6and 12-month study periods irrespective of the dose of islets transplanted and the site of islet implantation.

Two-way ANOVA revealed that both the dose of 3000 islets or the IP site resulted in significantly better plasma glucose levels than 1000 islets or the SC site for the 6-month group ( $p=0.0006$ and $p=$ 0.0067 , respectively). However, for the 12 -month study only the IP site had a significant advantage $(p=0.04)$. The potential influence of the small number of surviving animals (type II statistical error) in some groups of animals, especially in the 12-month study, were scrutinised. The analysis using the nonparametric one-way analysis of rank score with PROC NPARIWAY WILCOXON (SAS Institute Inc.) produced results that concurred with the above analyses using parametric tests.

18-month study group (Fig. 2). The starting level of hyperglycaemia in the diabetic controls and diabetic animals treated with islet grafts was not significantly different. None of the diabetic control animals survived the whole study period, but all remained diabetic until death (data not shown). The 3000 IP recipients achieved normoglycaemia on day 1 $(9.6 \pm 0.5 \mathrm{mmol} / \mathrm{l})$ while the day 7 plasma glucose level of $3000 \mathrm{SC}$ recipients was still significantly elevated $(19.4 \pm 3.1$ vs $8.6 \pm 0.3 \mathrm{mmol} / 1, p=0.0044)$. By day 14 , the mean glucose level between 3000 IP and $3000 \mathrm{SC}$ recipients was similar $(8.63 \pm 0.2$ vs $10.52 \pm 1.1 \mathrm{mmol} / \mathrm{l})$. In the first 13 months of the study, the glucose level of the 3000 IP animals was consistently lower than the 3000 SC animals, reaching significance for the third $(p=0.0006)$, eighth $(p=0.0057)$ and eleventh $(p=0.0102)$ month. None of the $3000 \mathrm{IP}$ recipients showed any evidence of exhaustion or decline in metabolic function for the whole 18 months. The glucose levels of transplanted animals and the normal controls were not significantly different throughout the whole 18 months.

Lifelong study group (Fig.3). Both the 3000 IP and 3000 SC animals were observed until their natural

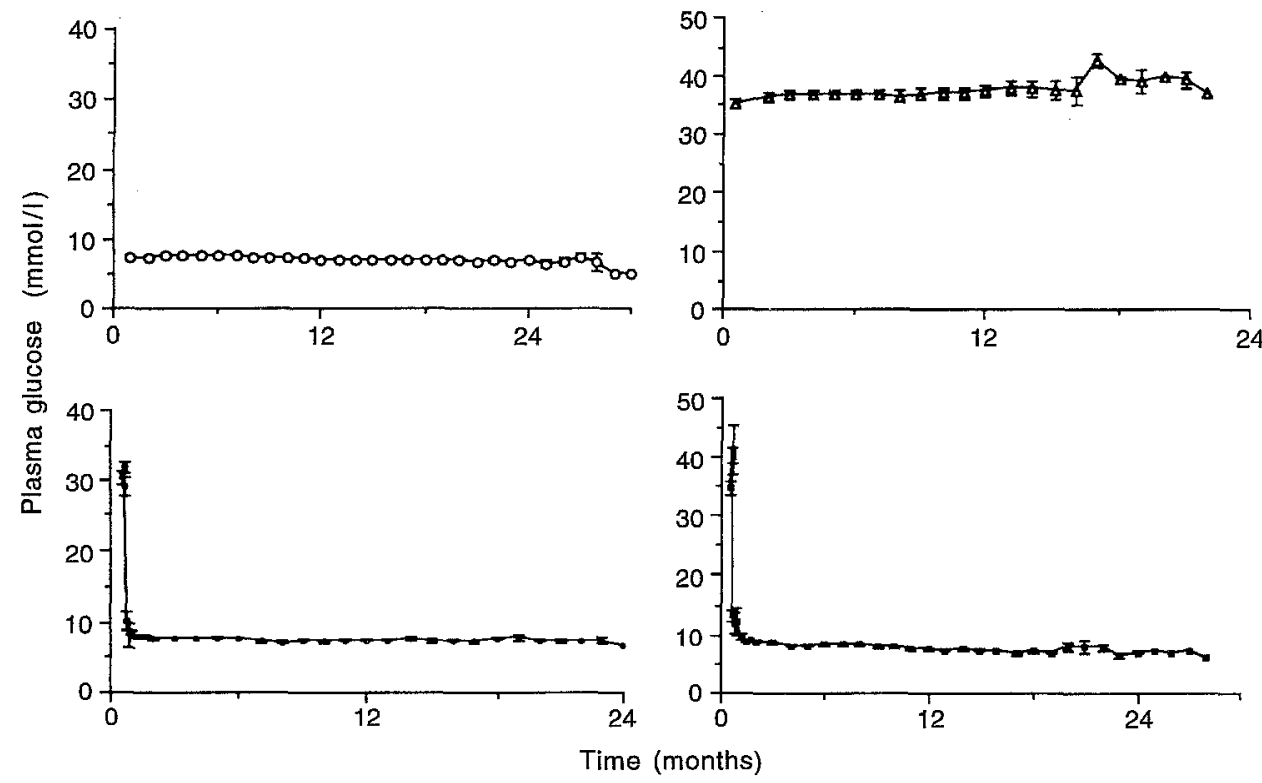

Fig. 3. Plasma glucose of rats made diabetic with $55 \mathrm{mg} / \mathrm{kg}$ streptozotocin and transplanted with 3000 islets IP or SC and followed lifelong, compared to normal and diabetic controls.

$(\mathrm{O}-\mathrm{O})$ normal controls, $(\mathbf{A}-\mathbf{A})$ diabetic controls, $(\bullet) 3000$ islets IP,

$(\square-) 3000$ islets SC.

Errors bars indicate SEM (where error bars are not visible error was smaller than the symbol). The surviving animals at each timepoint for non-diabetic control, diabetic control, IP transplanted and SC transplanted, respectively, was as follows: Day $0: 47,65,25,23 ; 3$ months: 47 , $65,23,23 ; 6$ months: $46,57,21,23$; 12 months: $42,26,21,19$; 18 months: $33,3,12,9 ; 24$ months: $4,0,1,2$ 


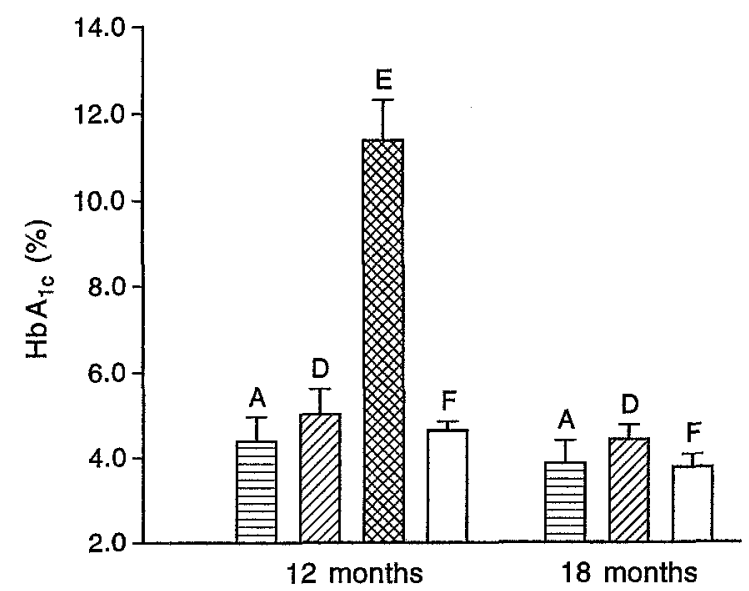

Fig. 4. $\mathrm{HBA}_{1 \mathrm{c}}$ levels of rats given 3000 islets either IP or SC at 12 months and 18 months, vs normal controls (A, 3000 IP; D, $3000 \mathrm{SC}$; E, diabetic control (12-month only, no diabetic controls survived to 18 months); F, normal control

death and none of the animals showed any evidence of graft failure throughout the period, the maximum follow-up being 28 months.

$H b A_{1 c}$ levels (Fig. 4). The presence of a high percentage of methaemoglobin in the haemolysate of the 6month study samples interfered with the clear separation of $\mathrm{HbA}_{1 \mathrm{c}}$, consequently no meaningful analysis was possible. This problem was overcome by more rapid processing of the samples from later groups. In the 12-month study, mean $\mathrm{HbA}_{1 \mathrm{c}}$ levels between the transplanted animals (3000 IP and 3000 SC) and normal controls were similar but were significantly lower than diabetic controls $(p=0.0001)$. In the 18-month study, the $\mathrm{HbA}_{1 \mathrm{c}}$ levels between the transplanted animals and normal controls were similar (no diabetic animals survived to the end of the 18-month study).

IVGTT of 6- and 12-month study groups (anaesthetised rats) (Groups 1-8, Fig. 5). In both the 6- and 12month studies, the fasting normoglycaemia observed in successfully transplanted animals was not significantly different from normal controls and their blood glucose levels were significantly lower than diabetic controls. Despite this the fasting insulin levels of diabetic, normal and transplanted animals were similar. In the 6-month study (groups 1-4, upper two graphs Fig.5), the primary insulin response of the normal controls $(58.63 \pm 13.9 \mathrm{mU})$ was significantly higher than all diabetic and transplanted animals with the exception of the $3000 \mathrm{IP}$ recipients $(24.02 \pm 5.5 \mathrm{mU})$ while the primary glucose response was similar between all groups. Although the glucose level of normal, $3000 \mathrm{IP}$ and 3000 SC animals was significantly lower than diabetic controls $(p=0.0001)$ at $60 \mathrm{~min}$, these did not attain the baseline glucose level but remained elevated in the hyperglycaemic range. In spite of this hyperglycaemic stimulus, there was no detectable second phase insulin response in all groups, the insulin level remaining at basal level.

The $\mathrm{K}$ values of the transplanted animals was not significantly different from the diabetic controls, but
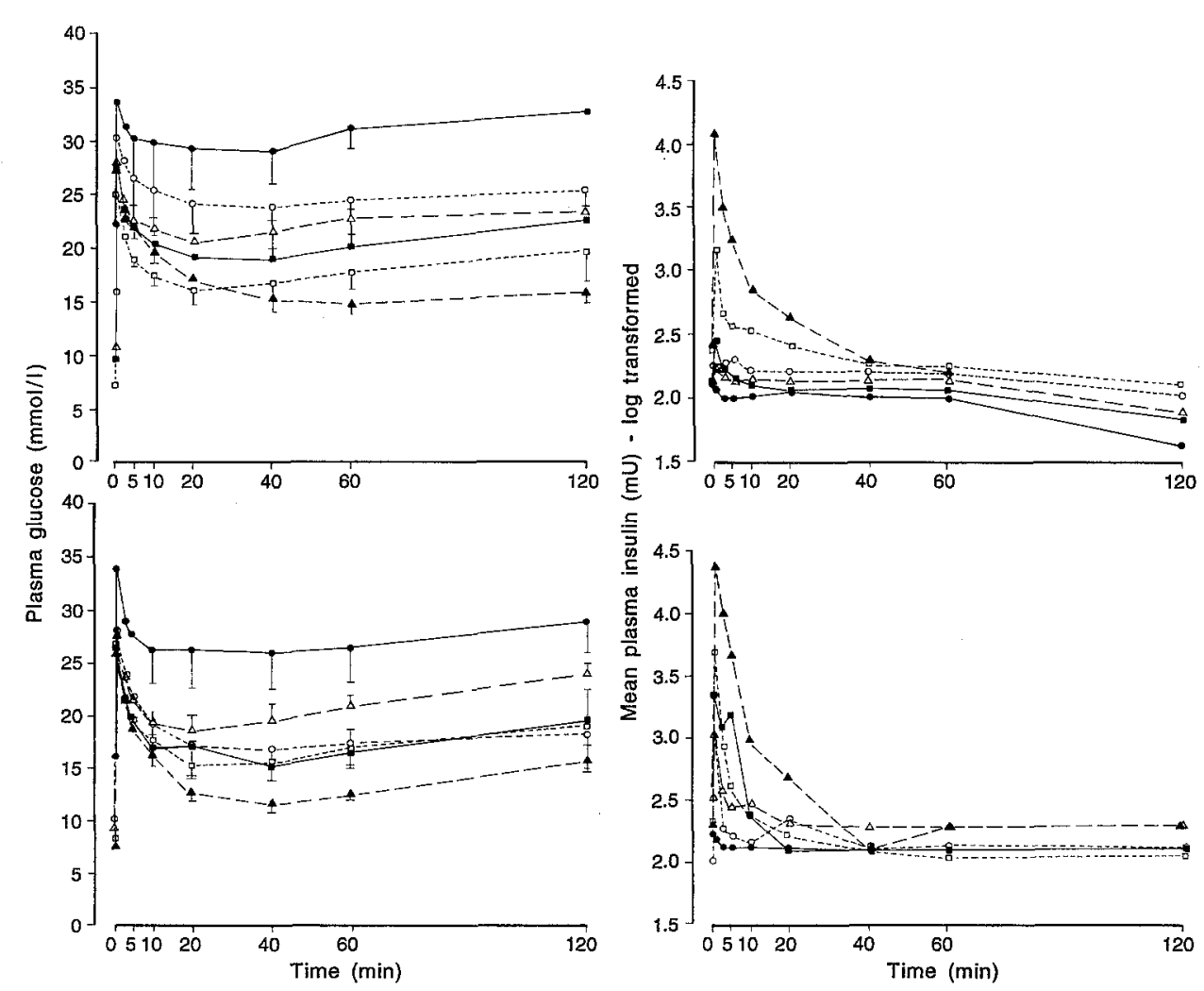

Fig.5. IVGTT glucose and insulin of rats given $65 \mathrm{mg} / \mathrm{kg}$ streptozotocin and 1000 , or 3000 islets IP or $\mathrm{SC}$, and tested under anaesthesia at 6 , and 12 months (vs control normals and diabetic untreated rats.

$\left(\Delta^{-\cdots} \Delta\right) 1000$ islets IP, $(0-\cdots-\circ)$ 1000 islets $S C,\left(\square^{----\square)} 3000\right.$ islets $\mathrm{IP},(\mathbf{\square}) 3000$ islets $\mathrm{SC},(\mathbf{\Delta}-\cdots \mathbf{\Delta})$ normal controls, $(\bullet)$ diabetic controls.

Upper two panels, 6 months; lower two panels, 12 months. Error bars indicate SEM 

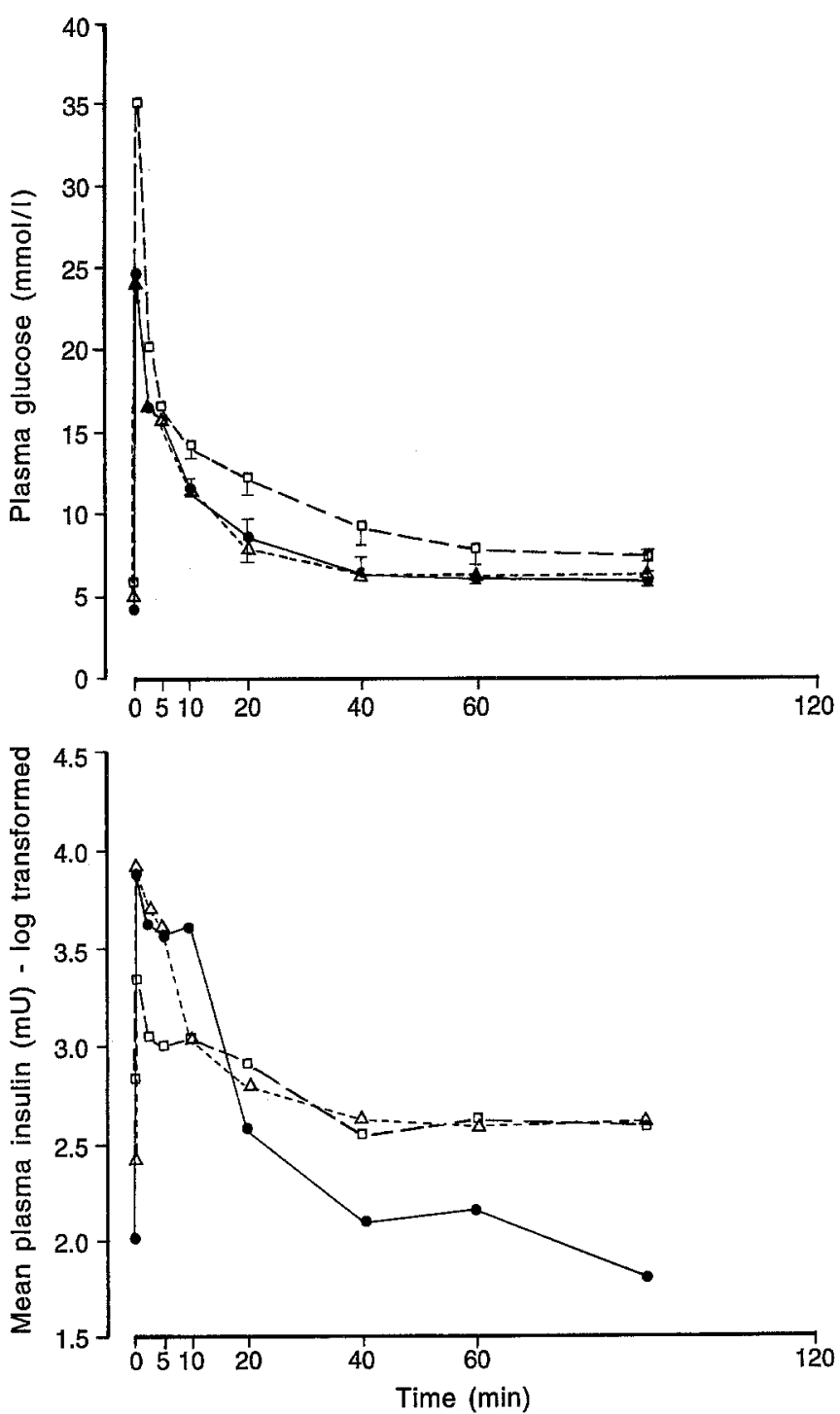

Fig. 6. IVGTT glucose and insulin of rats given $55 \mathrm{mg} / \mathrm{kg}$ streptozotocin then transplanted with 3000 islets IP or SC and tested at 18 months in conscious rats (vs control normals).

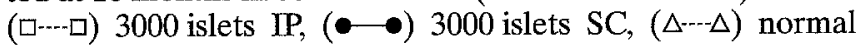
controls.

Note that no diabetic controls from this group survived 18 months. Error bars indicate SEM this may partly be due to low numbers in the surviving groups $(1000 \mathrm{IP}=1.14 \pm 0.18 \%, 3000 \mathrm{IP}=1.98 \pm$ $0.4 \%, \quad 1000 \mathrm{SC}=1.14 \pm 0.5 \%, \quad 3000 \mathrm{SC}=1.45 \pm$ $0.16 \%$ ). Only the normal controls had a significantly better $\mathrm{Kg}$ value than diabetic controls $(2.28 \pm 0.2 \%$ vs $0.58 \pm 0.2 \%, p=0.0051$ ).

In the 12-month study (groups 5-8, lower two graphs Fig. 5), the intergroup 1-min glucose and insulin responses were similar to the findings at 6 months. The lack of a second phase insulin response to a persistent hyperglycaemic state mentioned above was also noted here. However, the $\mathrm{K}$ value in the grafted animals ( $3000 \mathrm{IP}=2.56 \pm 0.4 \%$, $1000 \mathrm{SC}=2.47 \pm 0.5 \%, 1000 \mathrm{IP}=1.85 \pm 0.3 \%, 3000$ $\mathrm{SC}=1.83 \pm 0.2 \%$ ) was better than diabetic controls $(1.04 \pm 0.5 \%)$ but not different from normal controls $(3.52 \pm 0.2 \%, p=0.0017)$. There was no difference between the grafted animals.

IVGTT of 18-month study group (conscious rats) (groups 9 and 10, Fig. 6). The fasting glucose level between normal and transplanted animals was similar throughout the study, but 3000 IP animals had significantly higher fasting insulin levels than $3000 \mathrm{SC}$ animals $(p=0.0297)$. The IVGTT of rats given 3000 islets SC was virtually identical to normal, whilst the rats given 3000 islets IP showed a slightly elevated glucose levels that was significantly different at $p<0.05$ at $20 \mathrm{~min}$. The glucose and insulin levels at all subsequent time points were comparable. The 60- and 90-min glucose and insulin levels in all groups of animals had returned to baseline. The $\mathrm{K}$ values between $3000 \mathrm{IP}$ and $3000 \mathrm{SC}$ animals were similar $\quad(3000 \mathrm{IP}=4.27 \pm 0.53, \quad 3000 \mathrm{SC}=5.1 \pm 1.3)$ and not significantly different to normal controls $(5.26 \pm 0.8)(p=0.5873)$.

Glomerular basement membrane thickness (GBMT) measurements (Fig. 7). Normal rats showed progressive thickening of the glomerular basement membrane with increasing age but diabetes greatly in-

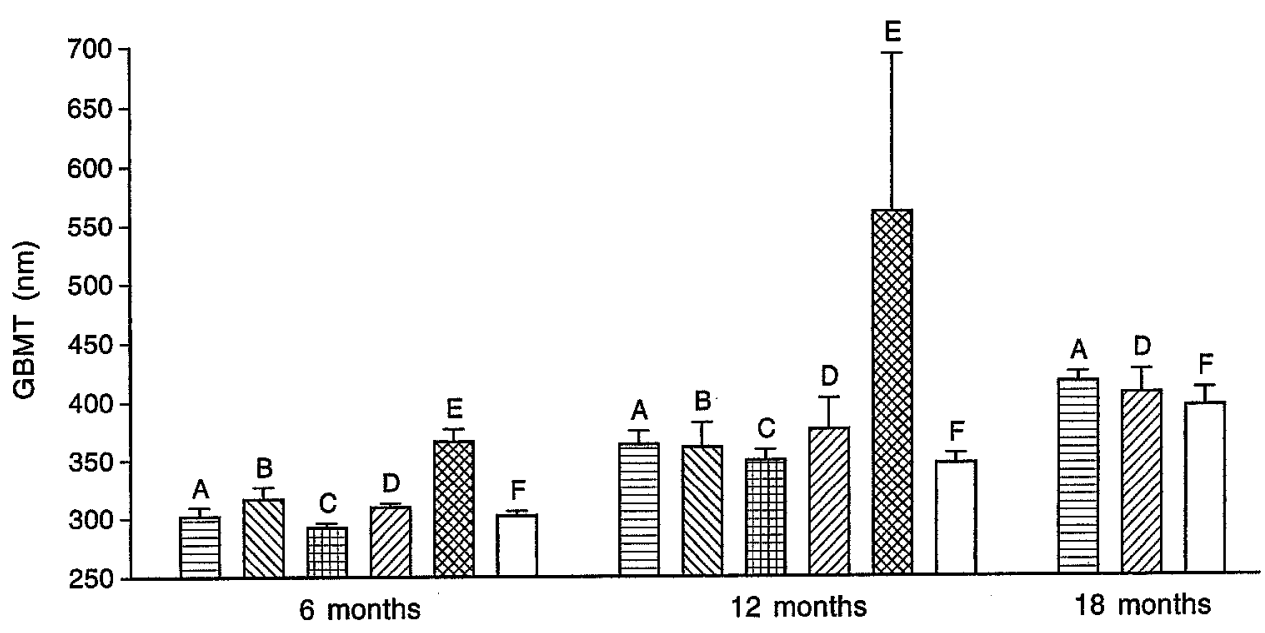

Fig. 7. GBMT values of rats given $65 \mathrm{mg} / \mathrm{kg}$ streptozotocin and 1000 , or 3000 islets IP or SC, and tested at 6 , and 12 months and rats given $55 \mathrm{mg} / \mathrm{kg}$ then transplanted with 3000 islets IP or SC and tested at 18 months (vs control normal rats and diabetic untreated rats). A, 3000 islets IP; B, 1000 islets SC; C, 1000 islets IP; D, 3000 islets $\mathrm{SC}$; E, diabetic control; $\mathbf{F}$, normal control. Note that no diabetic rats survived to 18 months 
creased the thickening process, at least up to 12 months. In the 6-month study, the GBMT of all successfully transplanted animals was similar to normal controls $(301.1 \pm 4.1 \mathrm{~nm})$ but were significantly less than diabetic untreated controls (365.9 \pm $10.8 \mathrm{~nm}, p=0.0001$ ). The GBMT of those $1000 \mathrm{SC}$ animals with persistent hyperglycaemia (316.6 \pm $9.0 \mathrm{~nm}$ ) was greater than the successfully transplanted and normal animals but failed to reach statistical significance.

In the 12-month study (Fig.7), the GBMT of all successfully transplanted and normal (345.5 \pm $9.4 \mathrm{~nm}$ ) animals was similar but significantly less than that of untreated diabetic controls (560.5 \pm $132.3 \mathrm{~nm}, p=0.0183$ ). The intraportal site was shown to have a significant influence on GBMT in the 6month study but this significance was not seen in the 12-month study. In both study periods, the dosage of islets did not influence GBMT.

In the 18-month study, none of the untreated diabetic controls survived. The GBMT of the transplanted and normal $(394.8 \pm 14.5 \mathrm{~nm})$ animals was similar.

Pancreatic insulin content. The insulin content of the pancreata retrieved from streptozotocin-treated rats was significantly lower than the insulin content of the normal pancreas, whether or not islet transplantation had been performed. The insulin content of the pancreas from animals treated with $65 \mathrm{mg} / \mathrm{kg}$ streptozotocin was lower than animals treated with $55 \mathrm{mg} / \mathrm{kg}$ streptozotocin but this did not reach statistical significance (insulin content of pancreas in $\mathrm{mU} \pm \mathrm{SEM}$ : $55 \mathrm{mg} / \mathrm{kg} \quad$ streptozotocin $=10.15 \pm 2.54, \quad 65 \mathrm{mg} / \mathrm{kg}$ streptozotocin $=22.84 \pm 6.98$, non-diabetic controls = $474 \pm 26$ ).

\section{Discussion}

The thesis that most, if not all, diabetic complications are a consequence of poor control of glucose metabolism is central to the concept of islet transplantation. Therefore, it is essential that islet transplantation can be shown to produce adequate long-term metabolic control, and prevent or reverse diabetic complications. Early studies of adult or neonatal islet transplantation were mostly in rodents, with relatively short follow-up, and were shown to produce normoglycaemia, or near normoglycaemia and improvement of indices such as weight gain, polyuria [27-29] glucose tolerance test [30], and blood lipids [31]. Early studies also showed that pancreatic islet transplantation could prevent [30] or reverse [32] some of the pathological changes in the kidney, such as increased mesangial matrix [30-34] and renal hypertrophy [35], but not others such as basement membrane thickening [33-35].
In a remarkably thorough series of studies of vascularised whole pancreas transplantation in the rat, Orloff and colleagues [11] have demonstrated that whole pancreas transplantation can produce lifelong precise control of glucose metabolism, as evidenced by non-fasting normoglycaemic, normal intraperitoneal glucose tolerance tests, and normal or slightly raised plasma insulin levels [11]. Prevention and reversal of mesangial changes in the kidneys of diabetic rats was demonstrated $[12,18]$. These workers have pointed out, correctly, that there are no studies demonstrating lifelong reversal of diabetes by islet transplantation, and that the metabolic status of any animals after islet transplantation, although improved, is not normal when examined by stringent criteria $[18,31,36-41]$. More recently, other studies of islet transplantation have failed to show reversal of diabetic kidney $[18,38]$ and eye lesions [42], the reason suggested being that the control of glucose metabolism achieved was not good enough [11]. Furthermore, doubt has been cast on earlier studies reporting reversal of diabetic lesions after islet transplantation because quantitative morphologic methods and a 'blind' protocol were not used [11].

Many of the early studies transplanted relatively small numbers of islets, usually between 600 and $1200[27,30,31,38,43]$, and in one case 2000 [28], and the islets were implanted into the peritoneal cavity $[31,43]$ or portal vein $[27,28,30,38]$. Expressing the mass of islet tissue transplanted as islet numbers has inaccuracies, but it probably gives a broad idea of the mass of tissue transplanted. The number of islets (of countable size) within the average adult rat pancreas is stated to vary from 600 to 4000 [44], although we have found the number of islets in an adult rat pancreas to be consistently more than 3000 , when counted by the method of Bensley [45] (D. Gray, unpublished data).

A reasonable argument to explain the imperfect (although greatly improved) glucose metabolism seen in the early studies of islet transplantation would be that insufficient tissue was transplanted in most studies. In fact the best metabolic profile from the above studies was seen in diabetic rats given 2000 islets intraportally [28]. If this thesis is correct, transplantation of greater numbers of islets would lead to correction of metabolism equal to that seen after whole pancreas transplantation. In turn, this should result in equally good amelioration of diabetic complications. A recent report comparing the effect of transplanting either $1200-2000$ islets or $2400-4000$ islets on prevention and reversal of diabetic neuropathy in streptozotocin-diabetic rats was in keeping with this concept [46], but unfortunately was terminated after 6 months. Further support comes from experimental transplantation of vascularized pancreas grafts, where transplantation of less 
than half the pancreas is consistently associated with abnormal glucose tolerance [47].

A further question concerns the aetiology of the late failure of islet grafts in some large animals after autogenous islet transplantation $[16,17]$. It is possible that this is also due to an inadequate quantity of islet tissue being transplanted. Islet failure may then occur due to "exhaustion", a concept well known to diabetologists [48], and recently given further weight by our own finding that exposure of islets to persistent hyperglycaemia for 6 months results in extensive loss of beta-cell mass [49]. In support of this idea, subtotal pancreatectomy has long been known to result in eventual onset of diabetes, after initial normoglycaemia [50].

A further point of importance is the site of transplantation. The intraperitoneal site has been shown to require much larger quantities of islet tissue than sites such as the intraportal one $[30,51,52]$. The reason is uncertain but may be due to poor implantation of the transplanted tissue. Recently a comparison between islets transplanted intraportally and those implanted beneath the renal capsule in the rat showed that the intraportal islets slowly failed after a few months, whilst renal subcapsular islets followed up to a year remained unchanged [19]. There are many possible reasons that could account for such a difference, but one would be persistent exposure of intraportal islets to hyperglycaemia (and other secretogogues) in the blood direct from the gut.

What length of time may be considered 'longterm' in a study of islet transplantation? In some studies long-term function equates to a period as short as 6 weeks! We would argue that "long-term" should ideally equate to the life-span of the transplanted animal. The normal life-span of the inbred rat varies from strain to strain, but is probably from 1.5 to 2.5 years.

Streptozotocin is commonly used to induce experimental diabetes for metabolic studies, but the diabetes produced varies greatly in severity, dependent upon the dose used [53]. Animals made severely diabetic (as by injection of a dose of $65 \mathrm{mg} / \mathrm{kg}$ ) have little residual pancreatic beta-cell function, and therefore provide a more realistic test of long-term graft function, but unfortunately these animals are weakened, either as a result of the severe diabetes or another toxic effect of the drug. We initially used the higher dosage of streptozotocin $(65 \mathrm{mg} / \mathrm{kg})$ but due to the long-term mortality found it necessary to introduce groups using a lower dosage $(55 \mathrm{mg} / \mathrm{kg})$ in an attempt to obtain truly long-term graft function. Although there have been earlier references to poor long-term survival following streptozotocin [53], we are perplexed as to why recent papers have failed to mention this drawback for long-term studies in diabetic animals. It is unlikely to be explained solely but rat strain differences, as in our experience the DA rat is the hardiest strain in relation to survival after induction of diabetes.

The abnormal IVGTT obtained from the 6- and 12-month study periods may be a function of the anaesthesia used. It is well-recognised that anaesthesia in humans produces abnormal glucose tolerance due to the stress response (adrenaline, cortisol release etc.) rather than the use of any specific anaesthetic agent. We have investigated the effect of a number of alternative anaesthetic agents in several strains of rats, including ketamine which was used in the present experiments, and could find no anaesthetic agent that was free of an adverse effect on IVGTT in any rat strain (unpublished data). Clearly rats undergoing anaesthesia are subject to considerable stress, and presumably this is the source of abnormal IVGTT. No mention of this effect was found in the textbooks of veterinary anaesthesia that we consulted. Interestingly, Trimble and colleagues [39] also noted similar results when phenobarbitone was used for IVGTT in rats. However, none of the recent publications have found the use of anaesthesia during IVGTT to be a problem: we are at a loss to explain the difference. The IVGTT performed on unanaesthetized animals from the 18-month study was completely different from that performed on anaesthetised animals, with rapid return to normoglycaemia at $40 \mathrm{~min}$ in normal controls. The IVGTT of rats given 3000 islets SC was virtually identical to normal at 18 months, whilst the rats given 3000 islets IP showed a slightly elevated glucose at $20 \mathrm{~min}$, but were otherwise normal.

This study showed that both intraportal and renal subcapsular islet grafts maintained normoglycaemia throughout the study period, up to a maximum longevity of 28 months. IP islet grafts did not show any signs of deteriorating endocrine function over time. At the lower dose of 1000 islets per recipient, more IP islet transplants reversed hyperglycaemia than renal SC grafts. Once normoglycaemia was restored by transplantation of 1000 or 3000 islets either into the liver or under the renal capsule, lifelong euglycaemia ensued. Furthermore, long-term normoglycaemia equated with protection from the development of diabetic nephropathy, as defined by the absence of the basement membrane thickening which developed in the long-term untreated diabetic animals.

It is difficult to reconcile the findings of our study with previous reports of failing intraportal grafts in the rodents. In one study by Orloff et al. [18] the initial intraportal islet graft and subsequent function. may have been inadequate. In a second study by Hiller et al. [19], both intraportal and renal subcapsular grafts of 1800 islets appeared to show good early function but the intraportal grafts began to fail at 6 months. The effect on diabetic nephropathy was not assessed. Our results, which are from a study using two levels of islet "dosage", contradict these find- 
ings. It is difficult to explain the reason other than to suggest that it may be due to rat strain differences.

The present study showed that intraportal islet isografts, containing 1000 or 3000 islets, had an immediate functional advantage over similar grafts placed under the renal capsule; a finding confirmed by van Suylichem et al. [54] but not observed by Hiller et al. [19]. This functional advantage of intraportal islet grafts has been noted in the dog where success in restoring prompt normoglycaemia after intraportal islet transplantation was dependent on the volume or dose of islet tissue transplanted [55], but similar number of islets implanted to the kidney capsule failed to restore normoglycaemia (G. Warnock, personal communication). In the monkey a functioning islet autograft to the renal subcapsule was only obtained with an exceptionally large yield of islets [56]. The most obvious explanation for the failure of renal subcapsular islet grafts to restore immediate normoglycaemia is the lack of an immediate blood supply resulting in hypoxia and subsequent cell death, the blood supply being better in intraportal grafts. Alternatively, the persistent hyperglycaemic state in animals with renal subcapsular islet grafts might itself interfere with neovascularization of the graft [57].

The methods used to assess the development of diabetic nephropathy are of considerable practical importance in studies of long-term glycaemia. Some authors have used light microscopic assessment [18], but Hirose et al. [26] have shown that light microscopic analysis is unreliable, and that the only reliable index of diabetic nephropathy in the rat is glomerular basement membrane thickening measured by the orthogonal intercept method on electron microscopic sections. Our study confirmed the rise in glomerular basement membrane thickness seen with age in normal rats, and showed that further thickening secondary to diabetes was prevented by islet transplantation, up to a maximum of 18 months.

In conclusion, these studies proved for the first time in an animal model of experimental diabetes that lifelong reversal of diabetes by islet transplantation with prevention of the development of diabetic nephropathy is an achievable goal.

Acknowledgements. This work was supported by a grant from the British Diabetes Association. C.K.L. was an MRC (UK) Training Fellow.

\section{References}

1. Brinchmann-Hansen O, Dahl-Jorgensen K, Sandvik L, Hanssen KF (1992) Blood glucose concentrations and progression of diabetic retinopathy: the seven year results of the Oslo study. BMJ 304: 19-22

2. Wang PH, Lau J, Chalmers TC (1993) Meta-analysis of effects of intensive blood-glucose control on late complications of type I diabetes. Lancet 341: 1306-1309
3. Nathan DM (1993) Long-term complications of diabetes mellitus. N Engl J Med 328: 1676-1685

4. The Diabetes Control and Complications Research Group (1993) The effect of intensive treatment of diabetes on the development and progression of long-term complications in insulin-dependent diabetes mellitus. $\mathrm{N}$ Engl J Med 329: 977-986

5. Bilous RW, Mauer SM, Sutherland DE, Najarian JS, Goetz FC, Steffes MW (1989) The effects of pancreas transplantation on the glomerular structure of renal allografts in patients with insulin-dependent diabetes. $\mathrm{N}$ Engl J Med 321: $80-85$

6. Ramsay RC, Goetz FC, Sutherland DE et al. (1988) Progression of diabetic retinopathy after pancreas transplantation for insulin-dependent diabetes mellitus. N Engl J Med 318: 208-214

7. Scheider A, Meyer-Schwickerath E, Nusser J, Land W, Landgraf R (1991) Diabetic retinopathy and pancreas transplantation: a 3-year follow-up. Diabetologia [Suppl 1] 34: 95-99

8. Fioretto P, Mauer SM, Bilous RW, Goetz FC, Sutherland DER, Steffes MW (1993) Effects of pancreas transplantation on glomerular structure in insulin-dependent diabetic patients with their own kidneys. Lancet 342: 1193-1196

9. Wilczek H, Solders G, Gunnarsson R, Tyden G, Persson A (1987) Effects of successful combined pancreatic and renal transplantation on advanced diabetic neuropathy: a oneyear follow-up study. Transplant Proc 19: 2327-2328

10. Van der Vliet JA, Navarro X, Kennedy WR, Goetz FC, Najarian JS, Sutherland DE (1988) The effect of pancreas transplantation on diabetic polyneuropathy. Transplantation 45: 368-370

11. Orloff MJ, Greenleaf GE, Urban P, Girard B (1986) Lifelong reversal of the metabolic abnormalities of advanced diabetes in rats by whole-pancreas transplantation. Transplantation 41: 556-564

12. Orloff MJ, Yamanaka N, Greenleaf GE, Huang Y, Huang D, Leng X (1986) Reversal of mesangial enlargement in rats with long-standing diabetes by whole pancreas transplantation. Diabetes 35: 347-354

13. Scharp DW, Lacy PE, Santiago JV et al. (1990) Insulin independence after islet transplantation into type I diabetic patient. Diabetes 39: 515-518

14. Warnock GL, Kneteman NM, Ryan EA, Rabinovitch A, Rajotte RV (1992) Long-term follow-up after transplantation of insulin-producing pancreatic islets into patients with type 1 (insulin-dependent) diabetes mellitus. Diabetologia 35: 89-95

15. Socci C, Falqui L, Davalli AM et al. (1991) Fresh human islet transplantation to replace pancreatic endocrine function in type 1 diabetic patients: report of six cases. Acta Diabetol 28: 151-157

16. Alejandro R, Cutfield RG, Shienvold FL et al. (1986) Natural history of intrahepatic canine islet cell autografts. J Clin Invest 78: 1339-1348

17. Sutton R, Gray DW, McShane P, Peters M, Morris PJ (1987) Metabolic efficiency and long-term fate of intraportal islet grafts in the cynomolgus monkey. Transplant Proc 19: $3575-3576$

18. Orloff MJ, Macedo C, Macedo A, Greenleaf GE (1987) Comparison of whole pancreas and pancreatic islet transplantation in controlling nephropathy and metabolic disorders of diabetes. Ann Surg 206: 324-334

19. Hiller WFA, Klempnauer J, Luck R, Steiniger B (1991) Progressive deterioration of endocrine function after intraportal but not kidney subcapsular rat islet transplantation. Diabetes 40: 135-140 
20. Sutton R, Peters M, McShane P, Gray DWR, Morris PJ (1986) Isolation of rat pancreatic islets by ductal injection of collagenase. Transplantation 42: 689-691

21. Scharp DW, Kemp CB, Knight MJ, Ballinger WF, Lacy PE (1973) The use of ficoll in the preparation of viable islets of Langerhans from the rat pancreas. Transplantation 16: 686-689

22. Lake SP, Anderson J, Chamberlain J, Gardner SJ, Bell PR, James RF (1987) Bovine serum albumin density gradient isolation of rat pancreatic islets. Transplantation 43: 805808

23. Gray DW, McShane P, Morris PJ (1986) The effect of hyperglycemia on isolated rodent islets transplanted to the kidney capsule site. Transplantation 41: 699-703

24. Albano JD, Ekins RP, Maritz G, Turner RC (1972) A sensitive, precise radioimmunoassay of serum insulin relying on charcoal separation of bound and free hormone moieties. Acta Endocrinol 70: 487-509

25. Moorhouse JA, Grahame GR, Rosen NJ (1964) Relationship between intravenous glucose tolerance and the fasting blood glucose level in healthy and in diabetic subjects. J Clin Endocrinol Metab 24: 145-159

26. Hirose K, Osterby R, Nozawa M, Gundersen HJ (1982) Development of glomerular lesions in experimental longterm diabetes in the rat. Kidney Int 21: 689-695

27. Kemp CB, Knight MJ, Scharp DW, Ballinger WF, Lacy PE (1973) Effect of transplantation site on the results of pancreatic islet isografts in diabetic rats. Diabetologia 9: 486491

28. Feldman SD, Hirshberg GE, Dodi G et al. (1977) Intrasplenic islet isografts. Surgery 82: 386-394

29. Finch DR, Wise PH, Morris PJ (1977) Successful intra-splenic transplantation of syngeneic and allogeneic isolated pancreatic islets. Diabetologia 13: 195-199

30. Gray BN, Watkins E (1976) Isolated islet transplantation in experimental diabetes. Aust J Exp Biol Med Sci 54: 57-70

31. Ziegler MM, Reckard CR, Barker CF (1974) Long term metabolic and immunological considerations in transplantation of pancreatic islets. J Surg Res 16: 575-581

32. Mauer SM, Steffes MW, Sutherland DE, Najarian JS, Michael AF, Brown DM (1975) Studies of the rate of regression of the glomerular lesions in diabetic rats treated with pancreatic islet transplantation. Diabetes 24: 280-285

33. Steffes MW, Brown DM, Basgen JM, Matas AJ, Mauer SM (1979) Glomerular basement membrane thickness following islet transplantation in the diabetic rat. Lab Invest 41 : 116-118

34. Weber CJ, Silva FG, Hardy MA, Pirani CL, Reemtsma K (1979) Effect of islet transplantation on renal function and morphology of short- and long-term diabetic rats. Transplant Proc 11: 549-556

35. Gotzsche O, Gunderson HJG, Osterby R (1981) Irreversibility of glomerular basement membrane accumulation despite reversibility of renal hypertrophy with islet transplantation in early experimental diabetes. Diabetes 30 : $481-485$

36. Vialettes B, Sutherland DE, Matas AJ, Payne WD, Najarian JS (1979) Amelioration of streptozotocin-induced diabetes in rats: effect of islet isografts on plasma lipids and other metabolic abnormalities. Metabolism 28: 489-494

37. Pipeleers D, Pipeleers-Marichal M, Kipnis D (1975) Metabolic and morphologic studies of long-term islet transplanted rats. Diabetes 24: 420

38. Yamamoto T, Kawamura J, Yoshida O, Tobe T (1984) Reversal of impaired renal function in rats with streptozoto- cin-induced diabetes by transplantation of isolated pancreatic islets: failure in preventing the progress of glomerulosclerosis. Nippon Geka Hokan 53: 721-735

39. Trimble ER, Karakash C, Malaisse-Lagae F, Vassutine I, Orci L, Renold AE (1980) Effects of intraportal islet transplantation on the transplanted tissue and the recipient pancreas. I. Functional studies. Diabetes 29: 341-347

40. Alderson D, Walsh TN, Farndon JR (1984) Islet cell transplantation in diabetic dogs: studies of graft function and storage. Br J Surg 71: 756-760

41. Merrell RC, Marincola F, Maeda M, Cobb L, Basadonna G (1985) The metabolic response of intrasplenic islet auto grafts. Surg Gynecol Obstet 160: 552-556

42. Naeser P, Andersson A (1983) Effects of pancreatic islet implantation on the morphology of retinal capillaries in alloxan diabetic mice. Acta Ophthalmol 61: 38-44

43. Ballinger WF, Lacy PE (1972) Transplantation of intact pancreatic islets in rats. Surgery 72: 175-186

44. Hebel R, Stromberg MW (1976) Anatomy of the laboratory rat. Williams and Wilkins, Baltimore

45. Bensley RR (1911) Studies on the pancreas of the guinea pig. Am J Anat 12: 297-388

46. Schmidt RE, Plurad SB, Olack BJ, Scharp DW (1983) The effect of pancreatic islet transplantation and insulin therapy on experimental diabetic autonomic neuropathy. Diabetes 32: $532-540$

47. Florack G, Ascherl R, Stadler J, Heidecke CD, Hesse U, Sutherland DER (1987) Endocrine function of canine segmental pancreatic grafts in relation to venous drainage site and duct management. Transplant Proc 19: 1019-1022

48. Unger RH, Grundy S (1985) Hyperglycaemia as an inducer as well as a consequence of impaired islet cell function and insulin resistance: implications for the management of diabetes. Diabetologia 28: 119-121

49. Gray DWR, Cranston D, McShane P, Sutton R, Morris PJ (1989) The effect of hyperglycaemia on pancreatic islets transplanted into rats beneath the kidney capsule. Diabetologia 32: 663-667

50. Allen FM (1922) Experimental studies in diabetes. Series III. The pathology of diabetes. I. Hydropic degeneration of islands of Langerhans after partial pancreatectomy. J Metab Res 1: 5-41

51. Sutherland DE (1981) Pancreas and islet transplantation. II. Clinical trials. Diabetologia 20: 435-450

52. Matas AJ, Payne WD, Grotting JC et al. (1977) Portal versus systemic transplantation of dispersed neonatal pancreas. Transplantation 24: 333-337

53. Junod A, Lambert AE, Stauffacher W, Renold AE (1969) Diabetogenic action of streptozotocin: relationship of dose to metabolic response. J Clin Invest 48: 2129-2139

54. Van Suylichem PTR, Strubbe JH, Houwing H, Wolters GHJ, Van Schilfgaarde R (1992) Insulin secretion by rat islet isografts of a defined endocrine volume after transplantation to three different sites. Diabetologia 35: 917-923

55. Warnock GL, Rajotte RV (1988) Critical mass of purified islets that induce normoglycemia after implantation into dogs. Diabetes 37: 467-470

56. Leow CK, Shimizu S, Gray DWR, Morris PJ (1994) Successful pancreatic islet autotransplantation to the renal subcapsule in the cynomolgus monkey. Transplantation 57: $161-164$

57. Cuthbertson RA, Koulmanda M, Mandel TE (1988) Detrimental effect of chronic diabetes on growth and function of fetal islet isografts in mice. Transplantation 46: 650654 